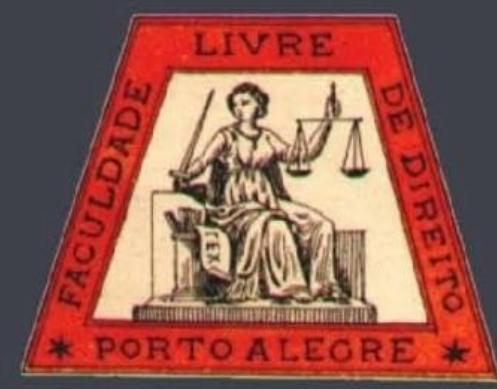

\title{
Os Centros Judiciários de Solução de Conflitos e Cidadania (CEJUSCS): a autocomposição em perspectiva
}

\footnotetext{
The Judicial Centers for Conflict Resolution and Citizenship (CEJUSCS): self-composition in perspective
}

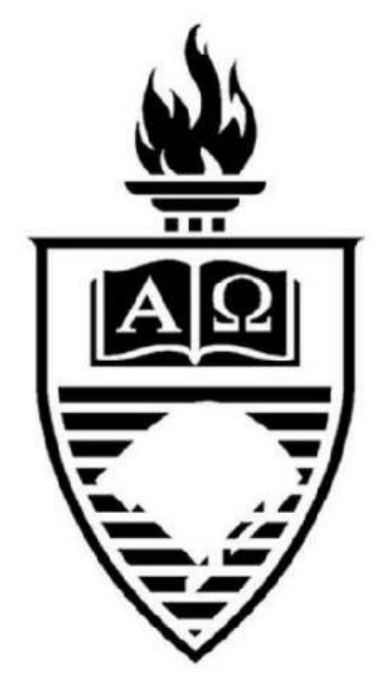

Karinne Emanoela Goettems dos Santos Universidade Federal de Pelotas

\section{UFRGS}




\title{
Os Centros Judiciários de Solução de Conflitos e Cidadania (CEJUSCS): a autocomposição em perspectiva
}

\author{
The Judicial Centers for Conflict Resolution and Citizenship (CEJUSCS): self-composition in \\ perspective
}

\author{
Karinne Emanoela Goettems dos Santos*
}

\begin{abstract}
REFERÊNCIA
SANTOS, Karinne Emanoela Goettems dos. Os Centros Judiciários de Solução de Conflitos e Cidadania (CEJUSCS): a autocomposição em perspectiva. Revista da Faculdade de Direito da UFRGS, Porto Alegre, n. 38, p. 257-276, ago. 2018.
\end{abstract}

\begin{abstract}
RESUMO
A alta litigiosidade registrada pelo Poder Judiciário nos últimos anos revela o uso demasiado de um modelo adversarial de solução de conflitos incapaz de assegurar a pacificação social e de garantir a efetividade do acesso à justiça como direito fundamental. É neste cenário que ressurge a autocomposição, através de rituais de solução de conflitos pautados no diálogo, como instrumento capaz de reeducar e transformar as relações sociais. É neste contexto, também, que é editada a Resolução no 125/2010 do CNJ, que estimula a autocomposição como política pública de resolução de conflitos e determina a criação dos Centros Judiciários de Solução de Conflitos e Cidadania CEJUSCs, em todo o Poder Judiciário, órgão este que passa a ser responsável pela realização de audiências de mediação e conciliação no tratamento dos conflitos. No âmbito desta temática, o presente trabalho pretende valorizar a autocomposição como caminho de remodelação do acesso à justiça e destaca o papel dos CEJUSCs como seu protagonista. Além disso, vale-se da análise quantitativa acerca do avanço dos CEJUSCs no âmbito da justiça estadual de primeiro grau, no período de 2014 a 2016, destacando, ainda, o trabalho realizado pelo CEJUSC da Comarca de Pelotas/RS. Ao final, espera-se demonstrar que, ainda que o consenso não se mostre perfeitamente internalizado em nossa cultura jurídica, é possível construir um modelo de justiça adequado à realidade contemporânea e que tenha a autocomposição em perspectiva, fazendo do CEJUSC o principal protagonista de um novo olhar sobre o acesso à justiça.
\end{abstract}

CEJUSCs. Autocomposição. Realidade social. Acesso à Justiça.

\section{PALAVRAS-CHAVE}

\section{SUMÁRIO}

Introdução. 1 A Resolução no 125/2010 do Conselho Nacional de Justiça e a criação dos Centros Judiciários de Solução de Conflitos e Cidadania - CEJUSCs. 2 Autocomposição e os círculos restaurativos: a Resolução nº 225/2016 do

\footnotetext{
* Professora Adjunta do Curso de Direito da Universidade Federal de Pelotas (UFPEL). Doutora em Direito pela UNISINOS (2015), graduação em Direito pela FURG/Rio Grande (1999), Especialização em Direito Processual Civil pela PUCRS (2001) e Mestrado em Direito pela UNISINOS (2006).
}

\section{ABSTRACT}

years reveals the excessive use of an adversarial model of conflict resolution incapable of ensuring social fication and guaranteeing the effectiveness of access self-composition resurfaces, through rituals of conflict resolution guided by dialogue, as an instrument capable of reducating and transforming social relations. It is in this which encourages self-determination as a public policy for conflict resolution, is issued and determines the creation of the Judicial Centers for Conflict Resolution and Citizenship - CEJUSCs, throughout the Judiciary, which is responsible for conducting mediation and conciliation hearings in the treatment of conflicts. In the scope of this as a way of remodeling access to justice and highlights the role of CEJUSCs as its protagonist. In addition, it draws the quantitative analysis of the progress of the period from 2014 to 2016, also highlighting the work carried out by CEJUSC of the Pelotas/RS Region. In the end, it is expected to demonstrate that, even though the it is possible to construct a model of justice that is appropriate to contemporary reality and that has selfprotagonist of a new look at access to justice.

\section{KEYWORDS}

CEJUSCs. Autocomposition. Social reality. Access to justice. 
Conselho Nacional de Justiça. 3 A autocomposição na perspectiva do acesso à justiça. $3.1 \mathrm{O}$ aspecto multidisciplinar da autocomposição e seus diversos mecanismos. $4 \mathrm{O}$ quadro da litigiosidade no país. 5 As estatísticas da autocomposição por meio da conciliação. 5.1 A gradativa implantação dos CEJUSCs no país e no Rio Grande do Sul. 5.2 O exemplo do CEJUSC da Comarca de Pelotas/RS. Conclusão. Referências.

\section{INTRODUÇÃO}

Décadas depois das chamadas ondas renovatórias de acesso à justiça, então propostas por Mauro Cappelletti, há muito ainda a ser trilhado em busca da sua materialização e efetividade, sobretudo no âmbito dos direitos humanos e, no Brasil, no âmbito dos direitos fundamentais.

Mas se há uma convergência acerca do modo como os conflitos devem ser tratados, esta vai ao encontro da necessidade de se construir um modelo de justiça novo ou diferente, especialmente adequado à realidade contemporânea. A alta litigiosidade registrada pelo Poder Judiciário nos últimos anos é tanto o reflexo da complexa vida em sociedade como também a evidência de que o clássico e polarizado modelo adversarial de solução de conflitos não consegue mais oferecer uma resposta constitucionalmente adequada de pacificação de conflitos.

É nesse cenário que ressurge a autocomposição, por meio de rituais de solução de conflitos pautados pelo diálogo, capazes de reeducar e transformar as relações sociais, recuperando, ainda, a humanidade dos procedimentos. Isso não significa dizer que, nesta remodelação do acesso à justiça, a jurisdição contenciosa venha a ser superada pela autocomposição, assim como o ritual dialogal não será aqui argumentado com o objetivo de evitar a judicialização dos conflitos. É sobre o acesso à justiça adequado e sobre a recuperação da dimensão histórica do procedimento de solução de conflitos que este trabalho pretende se debruçar.
E, no contexto dessa temática, este artigo pretende valorizar a autocomposição, retratando o seu avanço a partir da Resolução no 125/2010 do Conselho Nacional de Justiça, normativo este que desencadeou políticas públicas de incentivo ao uso da mediação e da conciliação e, posteriormente, da justiça restaurativa, como formas igualmente legítimas para a solução de conflitos. A fim de atender a esta expectativa, o mesmo normativo também determinou a organização, por parte das instâncias judiciárias, de Centros Judiciários de Solução de Conflitos e Cidadania - CEJUSCs, órgão especialmente responsável pela efetivação da autocomposição através do trabalho de mediadores, conciliadores (e facilitadores da justiça), assim designados cinco anos depois pelo Código de Processo Civil como auxiliares do juízo (art.165 do CPC).

Para tanto, retratar o avanço da autocomposição requer o acompanhamento da gradativa implantação dos CEJUSCs, razão pela qual este ensaio se vale de pesquisa quantitativa a fim de apurar o avanço dos CEJUSCs no âmbito da justiça estadual de primeiro grau, utilizando-se de dados extraídos do Relatório Justiça em Números do Conselho Nacional de Justiça, relativos ao período de 2014 a 2016, bem como vale-se dos dados do CEJUSC da Comarca de Pelotas/RS, destacando, como amostra, as audiências de conciliação do art.334 do CPC realizadas na sede desta Comarca no mesmo período. Por fim, para além do aspecto quantitativo, serão destacadas outras atividades realizadas pelo CEJUSC de Pelotas, que buscam atender às expectativas de políticas públicas de cidadania igualmente estimuladas pela Res.125/2010 do Conselho Nacional de Justiça. 
Ao final, espera-se demonstrar que, ainda que o consenso não se mostre perfeitamente internalizado em nossa cultura jurídica, é possível construir um modelo de justiça adequado à realidade contemporânea e que tenha a autocomposição em perspectiva, fazendo do CEJUSC o principal protagonista de um novo olhar sobre o acesso à justiça, sobretudo apto a tratar da conflituosidade própria deste novo século.

\section{A RESOLUÇÃO $\mathbf{N}^{\circ} \quad 125 / 2010$ DO} CONSELHO NACIONAL DE JUSTIÇA E A CRIAÇÃO DOS CENTROS JUDICIÁRIOS DE SOLUÇÃO DE CONFLITOS E CIDADANIA - CEJUSCS

Em 2010, o Conselho Nacional de Justiça publica a Resolução $\mathrm{n}^{\circ} 125$, que dispõe sobre a Política Judiciária Nacional de Tratamento Adequado dos Conflitos de Interesse no âmbito do Poder Judiciário. O normativo constitui um marco na promoção de políticas públicas voltadas ao estímulo do consenso como meio de tratamento dos conflitos e como instrumento de

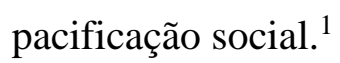

A Resolução instituiu os Núcleos Permanentes de Métodos Consensuais de Solução de Conflitos, compostos por magistrados e servidores com as atribuições de desenvolver, planejar, implementar, manter e aperfeiçoar ações voltadas ao cumprimento da política judiciária dos conflitos de interesse, e que serão responsáveis, junto aos tribunais, por criar os Centros Judiciários de Solução de Conflitos e Cidadania - CEJUSCs, para realização de conciliação e mediação, tanto na fase processual e pré-processual.

Segundo o $\operatorname{art}^{\circ}$ da Resolução, os CEJUSCs deverão ser instalados nos locais onde

\footnotetext{
1 SPENGLER, Fabiana Marion; SPENGLER NETO, Theobaldo. Mediação, Conciliação e Arbitragem: artigo por artigo. Rio de Janeiro: FGV Editora, 2016, p.104.
}

existam dois Juízos com competência para realização das audiências, que serão conduzidas por mediadores e conciliadores sem a presença dos magistrados. Ainda, de acordo com o art. $9^{\circ}$ da Resolução, o CEJUSC deve contar com um juiz coordenador, a quem cabe administrar e homologar acordos, bem como supervisionar o trabalho realizado por mediadores e conciliadores.

É importante contextualizar os CEJUSCs como espaços que adotam um ritual de tratamento dos conflitos completamente diverso do ambiente jurisdicional, pois enquanto os Centros são organizados por áreas temáticas, os Juízos são guiados pelo conceito formal de jurisdição, onde se aplica uma norma e se produzem efeitos concretos, sem muito interesse no diálogo e satisfação por inteiro de ambas as partes do conflito. $^{2}$

Além disso, para que ocorra a intervenção dos mediadores e conciliadores do CEJUSC, basta que haja interesse manifestado pelo cidadão, tanto na via judicial, para realização de mediação ou conciliação nos processos que já estão em andamento, como também na fase pré-processual.

$\mathrm{Na}$ fase processual, os CEJUSCs são responsáveis pela realização da audiência do art.334 do CPC, para tentativa de autocomposição antes mesmo de oferecida a defesa pelo polo passivo. Além disso, em qualquer fase ou andamento do processo, é possível redirecionar o caso da Vara em que o feito tramita para o CEJUSC, a fim de obter no Centro a intervenção dos auxiliares e nova oportunidade para autocomposição. Cabe ressaltar que questões latentes ao processo podem ser desveladas nesta oportunidade, ainda que não integradas à controvérsia, mas que, uma vez descomplicadas, podem contribuir para o desfecho amigável. Um exemplo claro decorre dos processos de inventário, nos quais os herdeiros podem obter,

2 SPENGLER, Fabiana Marion; SPENGLER NETO, Theobaldo. Mediação, Conciliação e Arbitragem: artigo por artigo, p.136. 
nas sessões de mediação ou conciliação, uma oportunidade renovada, mais aberta e informal, de comunicação e entendimento, com vistas à partilha amigável.

Já na fase pré-processual, em que não há litígio instaurado, o CEJUSC atua de fato sem a polarização própria do processo judicial, a partir da presença voluntária e espontânea dos sujeitos envolvidos no conflito. De acordo com o art.10 da Resolução, os CEJUSCs deverão oferecer obrigatoriamente um setor de atendimento préprocessual para sua atuação.

Em ambas as situações, seja para casos judicializados ou não judicializados, se as sessões conduzidas pelos Centros resultarem em acordo, este será homologado pelo juiz, constituindo título executivo judicial em favor dos transatores. A Resolução $\mathrm{n}^{\mathrm{o}} 125$ inclusive refere que, para efeito de estatística da produtividade, as homologações de casos judicializados são revertidas ao juízo de origem, permanecendo com o coordenador dos Centros a homologação dos casos pré-processuais (art. $8^{\circ}, \S 8^{\circ}$ ).

Mas o trabalho realizado no ambiente dos CEJUSCs não se reduz ao acompanhamento de conflitos, pois o Centro também está estruturado para realizar trabalhos de orientação dos cidadãos acerca do melhor caminho a ser utilizado na gestão dos seus conflitos, ${ }^{3}$ bem como para promover projetos sociais e educacionais de caráter preventivo e voltados para a construção da paz e para a convivência responsável, a exemplo do que vem sendo realizado pelo CEJUSC de Pelotas, o qual será destacado na sequência deste trabalho.

Por outro lado, a Resolução $n^{\circ}$ 125/2010 serviu também de incentivo a outras políticas públicas com objetivos semelhantes, a exemplo das edições do novo Código de Processo Civil $\left(\right.$ Lei $\left.n^{0} 13.105\right)$, da Lei de Mediação (Lei $n^{\circ}$
13.140) e da reformulação da Lei de Arbitragem (Lei $\left.\mathrm{n}^{\circ} 13.129\right)$, todas no ano de 2015.

Nesses passos, e embora já alterada em 2013, foi em 2016 que a Resolução no 125 recebeu, através da Emenda $\mathrm{n}^{\mathrm{o}}$ 2, importante aprimoramento em sua redação, sobretudo para adaptações em decorrência da edição do novo CPC (Lei 13.105/2015) e da Lei de Mediação (Lei 13.140/2015).

Entre outras alterações, a Emenda estabeleceu a criação do Cadastro Nacional de Mediadores Judiciais e Conciliadores, com a finalidade de auxiliar os tribunais ainda sem cadastro estadual. Outra importante alteração com a Emenda $n^{\circ} 2$ decorre da criação de parâmetros de remuneração dos mediadores, na linha do que preconiza o art.169 do novo CPC, os quais, até então, vinham prestando serviço voluntário. Além da tabela de remuneração, seguindo a linha do art.169 e art.167, $\$ 2^{\circ}$ do CPC, a Resolução passou a registrar a possibilidade de que os tribunais criem cadastro de auxiliares concursados, também de acordo com o que prevê o novo CPC.

Um importante destaque da Emenda ${ }^{\circ} 2$ é a criação do sistema de mediação e conciliação pré-processual digital, que pretende agilizar os procedimentos adotados por mediadores $\mathrm{e}$ conciliadores nos casos em que o ritual ocorre a partir da espontaneidade de ambos os mediandos ou conciliandos envolvidos.

Como se observa, a superveniência dos CEJUSCs e as políticas públicas de autocomposição a que estão destinados causam uma significativa ruptura na forma tradicional de tratamento de conflitos. Neste novo modelo, o papel central deixa de ser exercido pelo magistrado e passa a ser ocupado pelos próprios sujeitos em conflito, na medida em que o ritual da autocomposição, sustentado na comunicação e na retomada do diálogo, caracteriza-se

\footnotetext{
3 SPENGLER, Fabiana Marion; SPENGLER NETO, Theobaldo. Mediação, Conciliação e Arbitragem: artigo por artigo, p.140.
} 
essencialmente pela participação direta e efetiva do cidadão durante o seu procedimento.

Esse novo modelo de justiça também pode ser utilizado para o tratamento de conflitos com violência, a exemplo da justiça restaurativa, que mais recentemente está disciplina pela Resolução 225/2016 do CNJ e que a seguir será destacada.

\section{AUTOCOMPOSIÇÃO E OS CÍRCULOS RESTAURATIVOS: A RESOLUÇÃO $\mathbf{N}^{\circ}$ 225/2016 DO CONSELHO NACIONAL DE JUSTIÇA}

A autocomposição também tem obtido espaço e incentivo para sua utilização em conflitos com violência, sobretudo pela incapacidade ou dificuldade dos sistemas formais de justiça responderem adequadamente ao conflito social na sociedade contemporânea.

No final do século XX, a ONU passou a recomendar aos seus países membros a adoção da Justiça Restaurativa, especialmente para conflitos da área criminal, na busca de uma maior efetividade do acesso à justiça nesta seara, através da restauração das relações e da reparação de danos. $^{4}$

No Brasil, a Justiça Restaurativa veio oficialmente regulamentada pelo Conselho Nacional de Justiça através da Resolução ${ }^{\circ} 225$, em maio de 2016, na expectativa de incentivar a pacificação social por meio da aproximação e do diálogo entre o infrator, vítima e familiares, promovendo a compreensão do conflito entre os envolvidos e, quando possível, também a reparação dos danos.

As técnicas autocompositivas da justiça restaurativa, a exemplo dos círculos restaurativos,

\footnotetext{
4 BRASIL. Conselho Nacional de Justiça. Justiça Restaurativa - Horizontes a partir da Resolução 225 CNJ. Disponível em

http://www.cnj.jus.br/files/conteudo/arquivo/2016/08/4d63 70b2cd6b7ee42814ec39946f9b67.pdf>, Acesso em 03Julho2018.

${ }^{5}$ BRASIL. Poder Judiciário. TJRS. Programa Justiça Restaurativa para o Século XXI. Disponível em <
}

são adotadas por facilitadores capacitados que buscam sobretudo resgatar valores como respeito e empoderamento, a fim de evitar a repetição do conflito (art.2 ${ }^{\circ}$ e $9^{\circ}$ da Resolução no $225 / 2016$ ).

As práticas podem ser adotadas no âmbito processual ou pré-processual, ou ainda através de projetos executados em determinadas comunidades, a critério das Comarcas locais, com vistas à prevenção de conflitos. O Tribunal de Justiça do Rio Grande do Sul, a título de exemplo, instituiu o programa "Justiça Restaurativa para o século XXI", a fim de planejar estratégias de implantação e de utilização do paradigma restaurativo em ramos especiais da prestação jurisdicional, tais como na Infância e Juventude, na Violência Doméstica e Familiar contra a Mulher, na Execução Penal, no Direito de Família e no Direito Penal. ${ }^{5}$

Mas a prática dos círculos restaurativos não se restringe ao âmbito criminal, já que também é utilizada como técnica de prevenção de conflitos em ações de cidadania desenvolvidas pelos CEJUSCs, a exemplo dos projetos conduzidos na Comarca de Pelotas, destacados ao final deste trabalho.

O fato é que as práticas de mediação, conciliação e círculos restaurativos têm em seu ritual o lugar central da fala e da escuta, com o reconhecimento das responsabilidades recíprocas e com a gestão das emoções, ${ }^{6}$ restabelecendo, a partir disso, valores eventualmente esvaziados por ocasião do conflito, a exemplo do reconhecimento do outro.

E se tais práticas têm apresentado resultados, inclusive no âmbito dos conflitos com violência, é preciso destacar a autocomposição e seus diferentes rituais como instrumentos capazes de

https://www.tjrs.jus.br/export/poder_judiciario/tribunal_de _justica/corregedoria_geral_da_justica/projetos/projetos/ju stica_sec_21/J21_TJRS_P_e_B.pdf $>$, Acesso em 05 Maio.2018.

${ }^{6}$ ROSENBERG, Marsall B. Comunicação não-violenta: técnicas para aprimorar relacionamentos pessoais e profissionais. São Paulo: Ágora, 2006, p.42. 
oferecer ao cidadão em conflito uma perspectiva de solução por meio de procedimentos menos formais e mais humanizados.

\section{A AUTOCOMPOSIÇÃO NA PERSPECTIVA DO ACESSO À JUSTIÇA}

Mauro Cappelletti justificava a terceira onda renovatória de acesso à justiça incentivando reformas direcionadas para procedimentos ou rituais de solução de conflitos destinados a causas menos complexas, neles incluindo o trabalho de pessoas leigas ou paraprofissionais. É neste sentido que Cappelletti vai fazer referência aos métodos alternativos pela via do juízo arbitral, da conciliação e de incentivos econômicos para a solução de litígios fora dos tribunais. ${ }^{7}$

Especialmente no que se refere à conciliação, o processualista italiano retratou na época experiências bem sucedidas no Japão, Estados Unidos e França, assim como alertava para o fato de que a conciliação deve ser utilizada de modo a satisfazer efetivamente as partes e não apenas para servir de método a reduzir o congestionamento do Judiciário. ${ }^{8}$

Passadas algumas décadas desde o projeto Florença, o Brasil apenas recentemente tem fomentado políticas públicas de incentivo efetivo à autocomposição, sendo a Resolução 125/2010 do CNJ e o novo CPC exemplos deste desiderato. Mas apesar deste distanciamento, é possível observar uma mudança de perspectiva nos modelos de solução de conflitos e de acesso à justiça a partir do estímulo autocomposição.

Para Oscar Chase, os rituais de resolução de litígios são "instituições através das quais a vida social e cultural é mantida, provocada e alterada, ou como a mesma ideia foi expressa, constituída ou construída", 9 de modo que quanto

\footnotetext{
7 CAPPELlETTI, Mauro; GARTH, Bryant. Acesso à Justiça. Tradução de Ellen Gracie Northfleet. Porto Alegre: Fabris, 1988, p.81.

${ }^{8}$ CAPPELlETTI, Mauro; GARTH, Bryant. Acesso à Justiça, p.85-87.
}

mais for utilizada a autocomposição e mais resultados obtiver, mais familiaridade a comunidade jurídica terá com o ambiente do diálogo e maior capacidade os sujeitos eu a experimentam irão adquirir na gestão de seus conflitos.

Há que se destacar, portanto, o diálogo como técnica adequada no tratamento dos conflitos, ainda que, a partir dele, reflexamente ou naturalmente, venha a ocorrer uma redução da litigiosidade, pois, além de focar na reeducação dos sujeitos e na transformação de suas relações, a mediação, a conciliação e a justiça restaurativa, mecanismos que se utilizam basicamente do diálogo, passam a ser instrumentos também de prevenção dos novos conflitos.

Em síntese, falar de autocomposição como prática de solução de conflitos é reconhecer que há um compromisso das instituições, dos profissionais da área jurídica e inclusive do próprio cidadão com políticas públicas de pacificação social. E não se trata de uma opção, mas sim de uma necessidade. É a realidade social extremamente conflituosa que clama por essa adaptação. Recuperar a dimensão histórica e a humanidade dos procedimentos faz parte dessa mudança de perspectiva.

Ovídio Baptista da Silva esteve atento à essa realidade, manifestando sua preocupação com uma jurisdição não compatível com a realidade contemporânea, ao tratar de uma "falta de compreensão adequada aos fatores culturais que nos aprisionam, fazendo com que andemos em círculos, sem que nenhum progresso efetivo se tenha obtido". ${ }^{10}$ A proposta, portanto, seguindo os passos do mestre, é de adaptação do Direito à essa realidade conflituosa, comunicando-se com ela.

É preciso, portanto, compreender o conflito na sua dimensão histórica, valorizando a presença

${ }^{9}$ CHASE, Oscar G. Direito Cultura e Ritual: Sistemas de Resolução de conflitos no contexto da cultura comparada, p. 21 .

${ }^{10}$ SILVA, Ovídio Baptista da. Processo e Ideologia - o paradigma racionalista, página $\mathrm{X}$ do Prefácio. 
e participação efetiva do cidadão, então sujeito dessa relação conflituosa. Para Luis Alberto Warat, isso é possível a partir das potencialidades simbolizantes do outro, como sujeito que surge do reconhecimento do outro como alteridade constitutiva das diferenças, ${ }^{11}$ nas suas circunstâncias de tempo e espaço.

$\mathrm{O}$ que se quer afirmar, em outras linhas, é que os rituais tanto contenciosos como autocompositivos também são formadores e elementos transformadores das relações sociais. Se o ritual contencioso fomenta a beligerância, a autocomposição também é capaz de estimular a cultura do diálogo e da pacificação social. A prevenção de conflitos é notadamente um significativo resultado dessa remodelação, na medida em que a internalização de práticas pacificadoras das relações sociais é capaz de se antecipar ao próprio conflito.

\subsection{O aspecto multidisciplinar da autocomposição e seus diversos mecanismos}

A clássica concepção de heterocomposição requer a intervenção de uma autoridade que, ao se substituir às partes conflitantes, impõe-se sobre elas e entrega a sua decisão com vistas à resolução do conflito. $O$ caráter de substitutividade que lhe acompanha define a presença de um terceiro que se coloca sobre as partes e sobre elas ordena sua decisão. ${ }^{12}$ Neste cenário contencioso, rituais dialogais, focados no consenso, são estranhos à cultura beligerante de solução de conflitos.

Com a proposta de desenvolver outros meios de solução de conflitos, Francesco Carnelutti apresentou sua teoria acerca dos chamados equivalentes jurisdicionais, dentre os

\footnotetext{
${ }^{11}$ WARAT, Luis Alberto. Introdução Geral ao Direito III - O Direito não estudado pela teoria jurídica moderna. Porto Alegre: Fabris, 1997, p.26.

12 CHIOVEDA, Giuseppe. Instituições de direito processual civil. Tradução Paolo Capitaneo. Campinas: Bookseller, 1998, Vol.2, p.8.

${ }^{13}$ CARNELUTTI, Francesco. Instituciones del Proceso Civil. Volume I. Buenos Aires: EJEA, 1959, p.109.
}

quais se encontra a autocomposição. ${ }^{13}$ No México, Zamora y Castillo avança na doutrina do processualista italiano para colocar a autocomposição ao lado da jurisdição e da autotutela como meios igualmente legítimos de solução de conflitos. ${ }^{14}$

No Brasil, para Petronio Calmon, a autocomposição é um meio de solução de conflito de aspecto multidisciplinar, na medida em que envolve o estudo de perspectivas provenientes da antropologia, da comunicação, da tomada de decisão, ou ainda gerenciais, sociológicas e psicológicas, dentre outras, 15 abrangendo ciências variadas envolvidas na análise do conflito e em suas possíveis soluções. Entre diversas nomenclaturas utilizadas para designar a materialização da autocomposição (meios, métodos, mecanismos ou formas), com o referido doutrinador brasileiro é possível apresentar a negociação, a mediação e a conciliação como os principais mecanismos para a sua materialização. $^{16}$

Com essa perspectiva, a mediação é indicada em nosso país especialmente para os conflitos vivenciados por cidadãos com vínculo entre si (art. 165, $\S 3^{\circ}$ do CPC) ou ainda que para cidadãos que experimentam relações continuadas e que possivelmente podem perdurar após a ocorrência do conflito, a exemplo dos laços familiares e das relações de vizinhança. $\mathrm{Na}$ mediação, para além do acordo, o procedimento preocupa-se com o bem-estar das relações, a fim de que estas possam prosseguir transformadas em algo mais positivo e benéfico para os seus membros. A mediação é caracterizada pela intervenção de um terceiro imparcial e neutro, sem qualquer poder de decisão, a fim de auxiliar

14 ALCALÁ-ZAMORA Y CASTILlO, Niceto. Proceso, autocomposición y autodefensa. México: Universidad Atónoma Nacional de México, 1991, p.24 e p.71.

${ }^{15}$ CALMON, Petronio. Fundamentos da Mediação e da Conciliação. Brasília: Gazeta Jurídica, 2015, p.78-79.

${ }^{16}$ CALMON, Petronio. Fundamentos da Mediação e da Conciliação, p.87. 
os sujeitos do conflito a alcançar voluntariamente uma solução aceitável para ambos. É da essência do procedimento da mediação a negociação (tratativas diretas) entre os sujeitos, então intermediada pelo mediador. ${ }^{17} 18$

Já a conciliação, de viés mais prático, está especialmente voltada para as relações sem vínculo (art. 165, $\S 2^{\circ}$ do CPC). O acordo é a principal finalidade e o conciliador manifesta sua opinião sobre a solução mais coerente para o conflito. ${ }^{19}$

É fato que o juiz sempre teve, entre as suas atribuições, a função de conciliar as partes, o que resta mantido no novo CPC pelo art. 139, inciso V. Contudo, a norma vem acrescida de uma significativa preferência, no sentido de que a autocomposição seja promovida "preferencialmente com auxílio de conciliadores e mediadores judiciais", os quais, segundo o novo CPC, assumem a nova função de auxiliares do juízo (art.165 e seguintes).

É sob esse viés que o novo Código de Processo Civil apresenta o consenso como norma fundamental do processo. $\mathrm{O}$ art. $3^{\circ}, \S 3^{\circ}$ impõe a justiça consensual como um verdadeiro compromisso para a magistratura, ministério público e advocacia pública e privada, com vistas ao desenvolvimento de uma justiça consensual, o que redireciona, inevitavelmente, a atenção do acesso à justiça para um ambiente não contencioso, que deverá fortalecer a autocomposição tanto no espaço judicial como extrajudicial. O consenso é, portanto, norma fundamental do direito processual, e não mais uma mera alternativa de acesso à justiça.

E como reflexo desse fundamento, no âmbito do procedimento contencioso a audiência do art.334 do CPC tornou-se o primeiro passo

\footnotetext{
${ }^{17}$ CALMON, Petronio. Fundamentos da Mediação e da Conciliação, p.111.

${ }^{18}$ Importa registrar a posição contrária de Petronio Calmon no que respeita à realização da mediação no âmbito do Judiciário, pois para o autor trata-se de mecanismo livre e essencialmente privado, que não deveria ser aplicado ou
}

após a propositura da petição inicial de rito comum, com o objetivo de conciliar ou mediar o conflito antes mesmo da manifestação do réu. Apenas o desejo de todas as partes processais pela não realização da referida audiência irá retirar a solenidade de pauta. Outro reflexo do consenso como norma fundamental é a mudança do conceito de citação: segundo o art.238 do CPC, o réu não será mais citado para contestar, mas sim para integrar a relação jurídica processual. A polarização pode ou não ocorrer, a depender do que a audiência do art.334 poderá proporcionar a título de autocomposição.

Com essa perspectiva, o Código de Processo Civil expressa políticas públicas que buscam sobretudo qualificar o acesso à justiça a partir do estímulo ao diálogo e da solução dos conflitos por meio da autocomposição, o que impacta sobremaneira o paradigma da heterocomposição, rompendo, assim, com a lógica dos meios adversariais e polarizados de solução de conflitos.

\section{O QUADRO DA LITIGIOSIDADE}

$\mathrm{Na}$ contramão da autocomposição, historicamente a litigiosidade no país tem alcançado níveis alarmantes e mostra-se como evidência do exclusivismo da jurisdição como espaço destinatário de solução de conflitos, sobretudo no cenário de uma sociedade extremamente complexa e conflituosa.

No início da década de 90 do século XX, o Brasil apresentava cerca de quatro milhões de processos e no início dos anos 2000 já registrava

moldado em ambientes estatais e tampouco estar vinculada a uma atividade judicial. Ver em CALMON, Petronio. Fundamentos da Mediação e da Conciliação, p.131.

${ }^{19}$ CALMON, Petronio. Fundamentos da Mediação e da Conciliação, p.139-140. 
cerca de 20 milhões. A partir do ano de 2015, o país alcançou a marca de 100 milhões. ${ }^{20}$

De acordo com o último Relatório Justiça em Números, publicado pelo Conselho Nacional de Justiça em setembro de 2017, são cerca de 110 milhões de processos registrados em todo o Poder Judiciário para o ano de 2016. Há, portanto, uma constância na evolução da litigiosidade no país, ${ }^{21}$ que pode ser sintetizada na amostra dos últimos dois anos apurados pelo $\mathrm{CNJ}$, conforme se observa no quadro abaixo:
Nos anos-base de 2015 e 2016, confirma-se o retrato que marca a justiça estadual como ambiente do Judiciário que conserva quase $80 \%$ do volume de processos de todo o Poder Judiciário. Em média, do total de casos novos, $68 \%$ foram direcionados para a justiça estadual. Do total de casos pendentes, $79 \%$ permaneceram na justiça estadual.

No mesmo período de apuração, verifica-se o aumento de cerca de trinta milhões de casos novos em 2016 (dois milhões a mais do que os

\section{O acervo da Justiça Estadual frente ao Judiciário Nacional}

\begin{tabular}{|c|c|c|c|c|}
\hline & $\begin{array}{c}\text { Ano Base } \\
\text { (Milhões) }\end{array}$ & $\begin{array}{c}\text { Judiciário } \\
\text { (Milhões) }\end{array}$ & $\begin{array}{c}\text { Justiça Estadual } \\
\text { (Milhões) }\end{array}$ & $\begin{array}{c}\text { Concentração na } \\
\text { Justiça Estadual (\%) }\end{array}$ \\
\hline \multirow{3}{*}{ Total Processos } & 2015 & 101,2 & 77,9 & $77 \%$ \\
\cline { 2 - 5 } & 2016 & 109,1 & 82,8 & $76 \%$ \\
\hline \multirow{2}{*}{ Casos Novos } & 2015 & 27,3 & 18,9 & $69,3 \%$ \\
\cline { 2 - 5 } & 2016 & 29,4 & 19,8 & $67,4 \%$ \\
\hline \multirow{2}{*}{ Casos Pendentes } & 2015 & 73,9 & 59,0 & $79,8 \%$ \\
\cline { 2 - 6 } & 2016 & 79,7 & 63,1 & $79,3 \%$ \\
\hline
\end{tabular}

Fonte: Relatório Justiça em Números 2016 e 2017

Alguns fatores são preponderantes para sustentar esse acervo, quais sejam o ingresso significativo de processos a cada ano (30 milhões no ano de 2016) e uma alta taxa de congestionamento dos processos, em razão da estagnação dos processos pendentes, então provenientes dos anos anteriores.

A justiça estadual é o ramo do Judiciário que mais condensa esse volume de litigiosidade.

\footnotetext{
${ }^{20}$ BRASIL, Conselho Nacional de Justiça. Relatório Justiça em Números 2017. Disponível em: <http://www.cnj.jus.br/programas-e-acoes/pj-justica-emnumeros> Acesso em: 03Set.2017.
}

casos novos que ingressaram em 2015), dos quais cerca de 20 milhões foram destinados à justiça estadual. Também é significativo o aumento de casos pendentes, que de 2015 para 2016 evoluiu em 6 milhões de processos no Poder Judiciário, dos quais 4 milhões estão na justiça estadual. Isso acarreta, de 2015 para 2016, apurando casos novos e pendentes, o incremento de cerca de 10 milhões de processos em todo o Poder Judiciário, dos quais a metade se encontra na justiça estadual.

${ }^{21}$ SANTOS, Karinne Emanoela Goettems dos. Processo Civil e Litigiosidade - Para além da jurisdição dos conceitos sem coisas. Rio de Janeiro: Lumen Juris, 2016, p.50-51. 
A taxa de congestionamento, por sua vez, é fase de conhecimento e a fase de execução, de uma medida referencial que também permite processos criminais e não-criminais, no período avaliar esse quantitativo de processos novos e de $2015^{24}$ e $2016^{25}$.

Taxa de Congestionamento. $1^{\circ}$ Grau do Judiciário, Justiça Estadual e TJRS.

\begin{tabular}{|c|c|c|c|c|}
\hline \multirow{3}{*}{$\mathbf{2 0 1 5}$} & Fase do processo & Judiciário & Justiça Estadual & TJRS \\
\hline & Conhecimento & $63,4 \%$ & $66,3 \%$ & $59 \%$ \\
\cline { 2 - 5 } & Execução & $86,6 \%$ & $88,1 \%$ & $79 \%$ \\
\cline { 2 - 5 } & Geral & $75 \%$ & $77,2 \%$ & $69 \%$ \\
\hline \multirow{3}{*}{2016} & Conhecimento & $64 \%$ & $68 \%$ & $58 \%$ \\
\cline { 2 - 5 } & Execução & $87 \%$ & $87 \%$ & $80 \%$ \\
\cline { 2 - 5 } & Geral & $75,5 \%$ & $77,5 \%$ & $69 \%$ \\
\hline
\end{tabular}

Fonte: Relatório Justiça em Números 2016 e 2017

processos pendentes. Conforme já exposto em outro trabalho, a taxa de congestionamento sempre beirou a casa dos $80 \%$, se considerados os dados globais do Judiciário, sem diferenciar a justiça ou o grau de jurisdição. ${ }^{22}$ A diferença para o ano de 2015, quando ela cai para $75 \%$ na estadual, decorre da alteração da fórmula de cálculo que, a partir do Relatório 2016, passou a desconsiderar os dados relativos aos processos suspensos, sobrestados e em arquivo provisório, ${ }^{23}$ de modo que a sensível queda de congestionamento, em comparação com os anos anteriores, não pode ser motivo de comemoração.

Para compreender a margem de estagnação dos processos, o quadro abaixo toma por base o primeiro grau da justiça estadual, em comparação com os índices de todo o Poder Judiciário e, destacando, ainda, a presença do TJRS neste contexto. O quadro distingue, ainda, os índices da

\footnotetext{
${ }^{22}$ SANTOS, Karinne Emanoela Goettems dos. Processo Civil e Litigiosidade, p.54-55.

${ }^{23}$ Brasil. CNJ. Relatório Justiça em Números 2016, p.48 e 49.

${ }^{24}$ Brasil. CNJ. Relatório Justiça em Números 2016, p.68 e 124
}

Os dados permitem mensurar o congestionamento ainda maior na justiça estadual, tanto na fase de conhecimento como na fase de execução, bem como os entraves decorrentes da fase de execução dos processos judiciais. O TJRS, ainda que se encontre abaixo ainda da média do congestionamento, mantém, por exemplo, seu índice de quase $80 \%$ de congestionamento da fase de execução.

$\mathrm{Na}$ verdade, a média da taxa de congestionamento nunca baixou da casa dos $85 \%{ }^{26}$ e isso significa dizer que depois de toda uma tramitação do processo na fase de conhecimento, o processo irá encontrar um momento ainda mais estagnado, no qual o direito já restou reconhecido, mas cuja efetiva satisfação

\footnotetext{
${ }^{25}$ Brasil. CNJ. Relatório Justiça em Números 2017, p.110.

${ }^{26}$ Em alguns Tribunais da justiça estadual, a exemplo do TJRJ, o percentual de congestionamento chega a atingir a faixa de $94 \%$ dos processos, conforme Relatório Justiça em Números 2017, p.110.
} 
fica sujeita à sorte, sobretudo quanto à localização de patrimônio do devedor.

É preciso registrar, ainda, que as execuções fiscais têm um protagonismo relevante no índice do congestionamento em todo o Poder Judiciário, reforçando o fato de que o próprio poder público é um grande agente litigante. ${ }^{27}$ Nos anos de 2015 e 2016, as execuções fiscais foram responsáveis por uma estagnação de $92 \%$ e $91 \%$, respectivamente, de modo que, sem este índice, a fase de execução apresentaria um congestionamento bem inferior, na casa de $64,2 \%$ (2015) e $65,1 \%$ (2016), assim como haveria uma redução significativa da taxa geral. ${ }^{28}$

O fato é que o quadro da litigiosidade no Brasil aqui destacado merece a devida compreensão e reflexão sob o foco da autocomposição. São pilhas e prateleiras infindáveis de litígios, para os quais o tratamento vem sendo dirigido sob a lógica da abstração, com modelos de repetição e rapidez. Vale, dentro dessa lógica, a superioridade dos tribunais e seus enunciados vinculantes. ${ }^{29}$ Nestas circunstâncias, não se observa preocupação com os sujeitos e o devido cuidado com a natureza dos seus conflitos, assim como o próprio poder público não tem se desprendido para o diálogo para a composição dos seus litígios com o cidadão. Os conflitos experimentados pelo poder público raramente estão sob a mesa redonda.

Para Petronio Calmon, a estrutura do atual modelo de jurisdição e o modo como atividade jurisdicional é praticada não possui condições adequadas de atender à demanda social, seja em decorrência do excesso de litigiosidade, seja pela escassez de recursos humanos e materiais ou

\footnotetext{
27 Brasil. Conselho Nacional de Justiça. 100 Maiores Litigantes. Disponível em: < http://www.cnj.jus.br/images/pesquisas-

judiciarias/Publicacoes/100_maiores_litigantes.pdf>, Acesso em 06 Maio.2018.

${ }^{28}$ Brasil. CNJ. Relatório Justiça em Números 2017, p.113

${ }^{29}$ SANTOS, Karinne Emanoela Goettems dos. Processo Civil e Litigiosidade, p.159.
}

ainda pela forma obsoleta e burocratizada como está assentada. ${ }^{30}$

A litigiosidade, portanto, precisa ser desviada para que os conflitos sociais sejam devidamente tratados. O que se pretende defender aqui é que a autocomposição deve ser um caminho cogitado, ensinado e incentivado, a fim de que o modelo adversarial da heterocomposição seja utilizado somente para os casos em que o diálogo não tenha obtido êxito e sobre os quais a intervenção da autoridade judiciária se mostra necessária ou inevitável.

Esse argumento afasta qualquer hipótese de valorização da autocomposição como uma mera aposta para "desafogar" o Judiciário, em prol da desjudicialização dos conflitos. Reforça, também, o fato de que a autocomposição passa a ser uma necessidade na gestão inteligente de conflitos, inclusive como ferramenta estratégica de redução de custos. O conflito social, por si só, já representa um custo social. O conflito social sob litígio é, a partir disso, um duplo custo para a sociedade.

Não bastasse isso, no âmbito do modelo adversarial de jurisdição contenciosa, a satisfação de uma das partes implica necessariamente a insatisfação da outra. ${ }^{31}$ A sucumbência é o cerne de todo um trabalho realizado e do tempo despendido pela autoridade judicial sem qualquer certeza ou segurança de pacificação do problema. ${ }^{32}$ Definitivamente, a sentença pode finalizar o processo, mas não o conflito.

Tal perspectiva contrasta-se fatalmente com o modelo autocompositivo de solução de conflitos, no qual os próprios sujeitos envolvidos no conflito são estimulados a construir alternativas de transformação do conflito, na busca de um possível consenso. É o diálogo que

\footnotetext{
${ }^{30}$ CALMON, Petronio. Fundamentos da Mediação e da Conciliação. Brasília: Gazeta Jurídica, 2015, p.157.

${ }^{31}$ WARAT, Luis Alberto (ORG.). Em nome do acordo. A mediação no direito. $2^{a}$ edição. Buenos Aires: Almed, 1999, p.16.

32 ALCALÁ-ZAMORA Y CASTILlO, Niceto. Proceso, autocomposición y autodefensa. México: Universidad
} Atónoma Nacional de México, 1991, p.238. 
proporciona essa mudança de perspectiva do tratamento do conflito e de sua prevenção.

\section{AS ESTATÍSTICAS AUTOCOMPOSIÇÃO POR MEIO CONCILIAÇÃO}

DA

DA

Para contrastar os dados da litigiosidade, cabe destacar os avanços na autocomposição a partir dos índices de conciliação retratados pelo Relatório Justiça em Números do CNJ. A partir de 2016, o Relatório passou a divulgar tais índices para todo o Poder Judiciário, usando como critério o quantitativo de sentenças e decisões homologatórias de acordo. Tal indicador ainda não contempla as homologações de acordos ocorridos na fase pré-processual.

Para o ano de 2015, o índice de conciliação de todo o Poder Judiciário ficou em $11 \%$ das sentenças e decisões proferidas, índice este praticamente mantido no ano de 2016 (11,9\%).

Já na justiça estadual, para o ano de 2015 o índice médio de conciliação ficou em 9,4\%. O Tribunal que mais homologações registrou em 2015 foi o TJSE, com $21,7 \%$, tendo o TJRS registrado a marca de $7 \%$.

Para o ano de 2016, o índice de conciliação da justiça estadual pouco evoluiu, permanecendo no percentual de $10,9 \%$. No período, o maior índice de conciliação foi conquistado pelo TJCE, com $25 \%$ de sentenças homologatórias. Para o TJRS, foi registrado o percentual de $10,3 \%$ de sentenças desta natureza.

Ao lado do índice de conciliação, é importante observar o percentual de conciliadores, a partir dos dados que o Relatório divulga como força de trabalho auxiliar. Entre servidores, terceirizados, estagiários e juízes leigos, os conciliadores representavam 1,9 da

\footnotetext{
${ }^{33}$ Brasil. CNJ. Relatório Justiça em Números 2016, p.41.

${ }^{34}$ Brasil. CNJ. Relatório Justiça em Números 2017, p.63.

35 Brasil. Poder Judiciário. TJRS. Resolução 1124/2016/COMAG. Altera a res. n 1026/2014-COMAG,
}

força de trabalho auxiliar em $2015,{ }^{33}$ percentual este que evolui para $6,9 \%$ em $2016 .{ }^{34}$

Notadamente não se trata de um crescimento significativo, mas considerando o período recente de vigência do novo $\mathrm{CPC}$, há de se compreender que o ano de 2016 foi o primeiro momento de efetiva realização das audiências do art.334, sem olvidar o fato de que ainda não há uma distribuição ideal de auxiliares do juízo (mediadores e conciliadores) em todo o país, sobretudo pela falta de previsão ou organização sistêmica acerca de suas remunerações. No Rio Grande do Sul, de acordo com o art. $3^{\circ}$ da Resolução no 1124/2016/COMAG, os auxiliares prestarão serviço voluntário ou remunerado quando capacitados e cadastrados pelo Tribunal. ${ }^{35}$

$O$ fato é que os Centros Judiciários de Solução de Conflitos e Cidadania podem efetivamente sinalizar para uma mudança de perspectiva no tratamento dos conflitos sociais na contemporaneidade, desenhando um novo roteiro de acesso à justiça. $\mathrm{O}$ item a seguir, nessa linha, destaca a gradativa implantação dos CEJUSCs, especialmente no âmbito da justiça estadual de primeiro grau.

\subsection{A gradativa implantação dos CEJUSCs no país e no Rio Grande do Sul}

Em 2015 o Conselho Nacional de Justiça passou a divulgar os dados de instalação do CEJUSC, levando em consideração o exercício de 2014. Para traçar um perfil evolutivo da implantação dos CEJUSCs, os dados a seguir partem, portanto, do ano de 2014, até alcançar os anos de 2015 e 2016, período objeto da presente análise.

que disciplina os CEJUSCs no âmbito do Tribunal de Justiça do Rio Grande do Sul. Disponível em: $<$ http://www.tjrs.jus.br/site/processos/conciliacao/legislaca o.html> Acesso em 09Jul.2018. 
Evolução dos CEJUSCs. Período de 2014 a 2016.

\begin{tabular}{|c|c|c|c|}
\hline Tribunal & 2014 & 2015 & 2016 \\
\hline TJSP & 128 & 154 & 191 \\
\hline TJCE & 4 & 90 & 112 \\
\hline TJBA & 5 & 107 & 97 \\
\hline TJMG & 17 & 55 & 93 \\
\hline TJPR & 13 & 19 & 70 \\
\hline TJMT & 29 & 32 & 35 \\
\hline TJGO & 24 & 32 & 32 \\
\hline TJRS & 19 & 19 & 32 \\
\hline TJRJ & 19 & 1 & 27 \\
\hline TJRO & 25 & 25 & 26 \\
\hline TJAC & 2 & 21 & 26 \\
\hline TJAP & 0 & 0 & 21 \\
\hline TJSC & 10 & 18 & 22 \\
\hline TJDFT & 5 & 8 & 18 \\
\hline ТJPB & 15 & 15 & 17 \\
\hline TJTO & 5 & 5 & 16 \\
\hline ТЈМА & 16 & 15 & 15 \\
\hline TJMS & 4 & 9 & 9 \\
\hline TJRR & 4 & 4 & 8 \\
\hline TJPE & 7 & 0 & 7 \\
\hline TJPA & 5 & 6 & 7 \\
\hline TJES & 1 & 1 & 7 \\
\hline TJAM & 1 & 7 & 7 \\
\hline TJRN & 2 & 2 & 5 \\
\hline TJAL & 1 & 2 & 3 \\
\hline TJSE & 1 & 1 & 1 \\
\hline TJPI & nd & 1 & 1 \\
\hline TOTAL & & 649 & 905 \\
\hline
\end{tabular}

Fonte: Relatório Justiça em Números 2015 a 2017

O quadro demonstra alguns saltos em apenas dois anos, a exemplo dos tribunais do Ceará e da Bahia, que de quatro e cinco CEJUSCs implantados no ano de 2014, avançaram para 112 
e 97 CEJUSCs no ano de 2016, respectivamente. 36

O Rio Grande do Sul evoluiu de 19 para 32 CEJUSCs no período, ampliando seu índice de conciliação de 7\% em 2015 para 10,3\% em 2016. Atualmente, no site do TJRS estão identificados 34 CEJUSCs no primeiro grau da justiça estadual, 37 dentre os quais se encontra o CEJUSC da Comarca de Pelotas, cujos dados e trabalho serão destacados a seguir.
Com o advento do novo CPC, o trabalho do CEJUSC em Pelotas apresentou um significativo avanço, conforme se observa no quadro abaixo. As audiências do art.334 do CPC integram uma amostra das conciliações realizadas no período de apuração do presente trabalho, e demonstram uma evolução do número de audiências realizadas a partir da vigência do Código de Processo Civil, na sede da Comarca.

Audiências de Conciliação do art.334 CPC. CEJUSC Pelotas. Sede. 2015 a 2017

\begin{tabular}{|c|c|c|c|c|}
\hline Ano Base & $\begin{array}{c}\text { Audiências } \\
\text { Pautadas }\end{array}$ & $\begin{array}{c}\text { Audiências } \\
\text { Realizadas }\end{array}$ & $\begin{array}{c}\text { Acordos } \\
\text { Realizados }\end{array}$ & \% \\
\hline $\mathbf{2 0 1 5}$ & 499 & 177 & 32 & $18 \%$ \\
\hline $\mathbf{2 0 1 6}$ & 1.335 & & & \\
\hline $\mathbf{2 0 1 7}$ & 1.666 & 572 & 125 & $22 \%$ \\
\hline
\end{tabular}

Fonte: http://conciliacaopelotas.blogspot.com.br/

\subsection{O exemplo do CEJUSC da Comarca de Pelotas/RS}

O CEJUSC da Comarca de Pelotas é um exemplo do quanto a autocomposição pode efetivamente contribuir para o tratamento adequado do conflito social, tanto no âmbito judicial como extrajudicial. Desde sua implantação, em julho de $2011,{ }^{38}$ o CEJUSC de Pelotas foi se expandindo em postos na cidade e na região, partindo da sede da Comarca e alcançando, com sete anos de trabalho, as cidades próximas a partir da instalação de postos nas cidades de Morro Redondo e Pinheiro Machado, por exemplo, levando à comunidade o trabalho de mediadores, conciliadores e facilitadores da justiça.

\footnotetext{
${ }^{36}$ Ver Relatório Justiça em Números 2015, 2016 e 2017 páginas 70, 89 e 123 respectivamente.

37 BRASIL. Poder Judiciário. TJRS. NUMEPEC RS. Disponível em
}

Como se observa, no ano de 2015 foram pautadas cerca de 500 audiências de conciliação, das quais apenas 177 foram efetivamente realizadas com a presença de todas as partes. Do total de audiências realizadas, em $18 \%$ dos casos a conciliação foi exitosa. Em 2016, muito embora o percentual de acordo não tenha evoluído de forma significativa (apenas $4 \%$ de aumento), o fato é que triplicou o número de processos resolvidos por meio da conciliação. $\mathrm{O}$ mesmo avanço ocorreu em 2017, muito embora neste ano o percentual de acordos tenha reduzido.

O fato é que o avanço do número de audiências no período revela um avanço significativo da autocomposição, sobretudo a partir do estímulo do novo CPC.

http://www.tjrs.jus.br/site/processos/conciliacao/nucleo.ht ml>, Acesso em: 09.Jul.2018.

38 BLOG DO CEJUSC de Pelotas. Disponível em: $<$ http://conciliacaopelotas.blogspot.com.br/2011/> Acesso em: 03.Set.2017. 
E para além das estatísticas, o CEJUSC de Pelotas também tem se destacado pelas ações de cidadania, implementadas desde a sua constituição com a finalidade de desenvolver a conscientização e a reeducação das relações sociais com vistas à pacificação social. São atividades de prevenção e de tratamento dos conflitos por meio de palestras, oficinas e círculos restaurativos, realizados especialmente em escolas e condomínios habitacionais.

O projeto "Educação para a Paz" leva às escolas a importância do diálogo como instrumento de prevenção de conflitos e de promoção do entendimento e da pacificação social, abordando temas e conflitos próprios do ambiente escolar, experimentados por alunos, professores e gestores. ${ }^{39} \mathrm{~A}$ "Campanha drogas: caminho para o abismo", executada por sua vez em parceria com outras instituições, procura abordar o problema do vício como questão social, orientando a comunidade sobre condutas de prevenção e de tratamento ao uso de drogas. O projeto circula também pelas escolas e em outras instituições e locais que manifestarem interesse na execução do projeto. ${ }^{40}$

Já o projeto "Bons Vizinhos" leva aos condomínios habitacionais da região os círculos restaurativos de construção da paz, bem como palestras de conscientização e oficinas sobre boa vizinhança e direitos e deveres de vizinhos e de condôminos. $^{41}$

Por fim, desde 2016 o CEJUSC de Pelotas executa o projeto Pai Presente, ${ }^{42}$ que estimula e agiliza o reconhecimento espontâneo de paternidade por pais que ainda não constam

\footnotetext{
${ }^{39}$ BLOG DO CEJUSC Pelotas. Projeto Educação para a Paz. Disponível em: < http://conciliacaopelotas.blogspot.com.br/2017/09/escolamunicipal-do-areal-recebe-o.html> Acesso em: 05.Set.2017.

40 BLOG DO CEJUSC Pelotas. Campanha Drogas: caminho para o abismo. Disponível em: $<$ http://conciliacaopelotas.blogspot.com/2015/11/campanh a-drogas-caminho-para-o-abismo.html $>$ Acesso em: 05.Maio. 2017
}

registrados nas certidões de nascimento de seus filhos ou o acesso à investigação de paternidade para os casos em que a pessoa apontada como pai não reconheça esta circunstância espontaneamente. $\mathrm{O}$ projeto, ainda, promove reflexões acerca da importância da presença dos pais na criação dos filhos, seus direitos e deveres.

Como se observa, o Centro Judiciário de Solução de Conflitos e Cidadania de Pelotas é referência no Estado do Rio Grande do Sul, seja no que se refere ao atendimento das políticas públicas de autocomposição desencadeadas pela Resolução 125/2010 do CNJ, seja pela execução de ações de cidadania, as quais, para além das estatísticas, revelam a determinação da coordenação do Centro de todos os demais profissionais - mediadores, conciliadores e facilitadores da justiça- que se empenham há sete anos, inclusive voluntariamente, no desenvolvimento da cultura da paz e da materialização da autocomposição na perspectiva do acesso à justiça.

\section{CONCLUSÃO}

No âmbito do modelo de justiça guiado pela heterocomposição, a decisão judicial impõe-se sobre as partes, criando um perdedor sucumbente em face de um vencedor. Já na autocomposição, além de não se mostrar cabível a linguagem de vencedor e perdedor, a satisfação é notadamente recíproca, na medida em que a solução do conflito é uma construção dos próprios sujeitos, imprimindo traços sobretudo personalíssimos na resolução dos conflitos.

41 BLOG DO CEJUSC Pelotas. Projeto Bons Vizinhos. Disponível em: http://conciliacaopelotas.blogspot.com.br/2016/06/projetobons-vizinhos-promove-paz-no.html>. Acesso em 05 Maio. 2018

42 BLOG DO CEJUSC Pelotas. Projeto Pai Presente. Disponível em:

http://conciliacaopelotas.blogspot.com/2016/05/foro-depelotas-lanca-projeto-pai.html>, Acesso em: 05.Maio.2018. 
O advento da Resolução $n^{\circ}$ 125/2010 do $\mathrm{CNJ}$ e o reforço dos rituais consensuais trazido pelo novo CPC impactaram esse modelo clássico, ao tempo em que possibilitaram, aos poucos, uma compreensão diferenciada acerca dos conflitos sociais na contemporaneidade e sobretudo quanto ao modo de tratamento que a eles de ser proporcionado.

Ademais, não se pode mais tratar um conflito na contemporaneidade com os mesmos métodos utilizados nos séculos passados, de modo que, neste contexto, a autocomposição em perspectiva mostra-se como instrumento de significativa remodelação do acesso à justiça, bem como pode trazer uma resposta mais adequada à natureza dos conflitos da atual realidade social, cujo perfil têm revelado cada vez mais um retorno à intolerância e ao ressurgimento de microfascismos em meio à diversidade cultural e social, logicamente não experimentados no momento em que o direito processual nasce como ciência para o tratamento de conflitos nos séculos passados.

Nesse patamar de mudanças, a presença dos CEJUSCs no âmbito do Poder Judiciário é fundamental, sobretudo por protagonizar a materializar a autocomposição como procedimento mais humanizado na medida em que valoriza o papel dos sujeitos que experimentam o conflito em sua essência, respeitando sua dimensão e natureza.

Os CEJUSCs estão compostos por mediadores, conciliadores e facilitadores da justiça restaurativas. Coordenados por um magistrado, devem estar implementados no país em Comarcas com duas ou mais varas judiciais, para intervir nos casos judicializados ou não judicializados através de práticas de mediação, conciliação e justiça restaurativa.

Isso não significa dizer que, nesta remodelação do acesso à justiça, a jurisdição contenciosa venha a ser superada pela autocomposição, mas sim que deve estar igualmente ao seu lado, deixando para a heterocomposição apenas os conflitos não tocados ou solucionados pelo diálogo. É sob esse viés que o novo Código de Processo Civil apresenta o consenso como norma fundamental do processo. $\mathrm{O}$ art. $3^{\circ}, \S 3^{\circ}$ impõe a justiça consensual como um verdadeiro compromisso para a magistratura, ministério público e advocacia pública e privada, com vistas ao desenvolvimento de uma justiça consensual, o que redireciona, inevitavelmente, a atenção do acesso à justiça para um ambiente não contencioso.

Por outro lado, o quadro da litigiosidade apresentado neste trabalho, ao retratar as proporções do contencioso, quer destacar a beligerância como um hábito que pode ser reconfigurado. Além disso, se o ritual consensual é uma escolha, motivos não faltam para que os conflitos sejam direcionados ou redirecionados para a autocomposição, sobretudo porque a construção da solução do problema com o envolvimento dos próprios sujeitos, para além da lógica da sucumbência, transforma as relações sociais e auxilia inclusive na prevenção de novos conflitos. Definitivamente, a gestão de conflitos é uma ciência que requer maior atenção.

A justiça consensual é uma forma de adaptação do próprio direito à sociedade contemporânea e sua conflituosidade. Através do diálogo, impacta-se a distância entre o jurídico e social. A comunicação efetiva entre os sujeitos do conflito não só os aproxima como qualifica o ritual, trazendo maior satisfação na solução encontrada com a participação direta de todos os envolvidos. A essência desta nova proposta está justamente na valorização do cidadão e na compreensão das especificidades do conflito por ele experimentado. Os CEJUSC, por sua vez, são protagonistas desta mudança de perspectiva.

Ainda, a gradativa implantação dos CEJUSCs é uma evidência de que, ainda que o ritual consensual não tenha ainda espaço 
significativo em nossa cultura jurídica, é possível construir um modelo de justiça que tenha a autocomposição em perspectiva, capaz de compreender o conflito na contemporaneidade e apto a transformar e reeducar as relações sociais, em busca da efetividade do acesso à justiça. $\mathrm{O}$ trabalho exercido pelo CEJUSC da Comarca de Pelotas é um exemplo de que tal remodelação é possível.

Se o momento requer uma revolução da cultura de solução de conflitos, os CEJUSCs são o "centro" dessa revolução e a autocomposição sua perspectiva necessária, sobretudo para a concretude, em uma sociedade complexa e conflituosa, do direito fundamental de acesso à justiça, pois, sem a adequação necessária, de acordo com Zamora y Castillo, "el mayor escollo con que tropieza y tropezará el proceso, por muy perfectas que sean las leyes que lo encuadren, es la naturaleza humana". ${ }^{43}$

\section{REFERÊNCIAS}

ALCALÁ-ZAMORA Y CASTILLO, Niceto. Proceso, autocomposicion y autodefesa. México: Universidad Atónoma Nacional de México, 1991.

BLOG CEJUSC da Comarca de Pelotas. Disponível em: < http://conciliacaopelotas.blogspot.com.br/2017/09/escola-municipal-do-areal-recebe-o.html> Acesso em: 06 Maio.2018.

BRASIL. Conselho Nacional de Justiça. 100 Maiores Litigantes. Disponível em: < http://www.cnj.jus.br/images/pesquisas-judiciarias/Publicacoes/100_maiores_litigantes.pdf>, Acesso em 06 Maio. 2018

BRASIL, Conselho Nacional de Justiça. Relatório Justiça em Números 2017. Disponível em: <http://www.cnj.jus.br/programas-e-acoes/pj-justica-em-numeros> Acesso em: 17 Set.2017.

BRASIL, Conselho Nacional de Justiça. Relatório Justiça em Números 2016. Disponível: em <http://www.cnj.jus.br/files/conteudo/arquivo/2016/10/b8f46be3dbbff344931a933579915488.pdf> Acesso em: 17 Set.2017.

BRASIL. Conselho Nacional de Justiça. Relatório Justiça em Números 2015. Disponível em: <ftp://ftp.cnj.jus.br/Justica_em_Numeros/relatorio_jn2014.pdf >. Acesso em: 17 Set.2017. BRASIL. Conselho Nacional de Justiça. Justiça Restaurativa - Horizontes a partir da Resolução 225 CNJ. Disponível em <http://www.cnj.jus.br/files/conteudo/arquivo/2016/08/4d6370b2cd6b7ee42814ec39946f9b67.pdf>, Acesso em 03 Jul.2018.

BRASIL. Poder Judiciário. TJRS. Programa Justiça Restaurativa para o Século XXI. Disponível em $<$

https://www.tjrs.jus.br/export/poder_judiciario/tribunal_de_justica/corregedoria_geral_da_justica/pro jetos/projetos/justica_sec_21/J21_TJRS_P_e_B.pdf>, Acesso em 05 Maio.2018.

\footnotetext{
43 ALCALÁ-ZAMORA Y CASTILlO, Niceto. Proceso, autocomposición y autodefensa. México: Universidad Atónoma Nacional de México, 1991, p.238.
} 
BRASIL. Poder Judiciário. TJRS. Programa Justiça Restaurativa para o Século XXI. Relatório de 2015. Disponível <http://www.tjrs.jus.br/export/poder_judiciario/tribunal_de_justica/corregedoria_geral_da_justica/pr ojetos/projetos/justica_sec_21/Relatorio_de_Gestao_2015_Programa_JR21_TJRS.pdf> Acesso em 06 Maio.2018.

. Poder Judiciário. TJRS. Resolução 1124/2016/COMAG. Altera a res. n 1026/2014-COMAG, que disciplina os CEJUSCs no âmbito do TJRS. Disponível em: < http://www.tjrs.jus.br/site/processos/conciliacao/legislacao.html> Acesso em 09Jul.2018.

CALMON, Petronio. Fundamentos da Conciliação e da Mediação. Brasília: Gazeta Jurídica, 2015. CAPPELLETTI, Mauro; GARTH, Bryant. Acesso à Justiça. Tradução de Ellen Gracie. Porto Alegre: Fabris, 1988.

CARNELUTTI, Francesco. Instituciones del Proceso Civil. Volume I. Buenos Aires: EJEA, 1959. CHASE, Oscar G. Direito Cultura e Ritual: Sistemas de Resolução de conflitos no contexto da cultura comparada. $1^{a}$ edição. Tradução de Sérgio Arenhart, Gustavo Osna. São Paulo: 2014.

CHIOVEDA, Giuseppe. Instituições de direito processual civil. Tradução Paolo Capitaneo. Campinas: Bookseller, 1998, Vol.2.

ROSENBERG, Marsall B. Comunicação não-violenta: técnicas para aprimorar relacionamentos pessoais e profissionais. São Paulo: Ágora, 2006 p.42

SILVA, Ovídio A. Baptista da. Processo e Ideologia - o paradigma racionalista. Rio de Janeiro: Forense, 2006.

SANTOS, Boaventura de Sousa. Para uma Revolução Democrática da Justiça. São Paulo Cortez, 2011.

SANTOS, Karinne Emanoela Goettems dos. Processo Civil e Litigiosidade. Rio de Janeiro: Lumen Juris, 2016.

SPENGLER, Fabiana Marion; SPENGLER NETO, Theobaldo. Mediação, Conciliação e Arbitragem: artigo por artigo. Rio de Janeiro: FGV Editora, 2016.

WARAT, Luis Alberto. Introdução Geral ao Direito III - O Direito não estudado pela teoria jurídica moderna. Porto Alegre: Fabris, 1997.

WARAT, Luis Alberto (ORG.). Em nome do acordo. A mediação no direito. $2^{\text {a }}$ edição. Buenos Aires: Almed, 1999.

Recebido em: 09/07/2018 Aceito em: 24/08/2018 
